\title{
WITTGENSTEIN CONTRA A DOUTRINA DA PREDESTINAÇÃO: religião e ética como sistema de referências
}

\author{
Wittgenstein against doctrine of \\ predestination: religion and ethics like \\ system of references
}

\author{
Horacio Luján Martínez
}

Doutor em Filosofia, professor de ética contemporânea no Mestrado em filosofia da Universidade Estadual do Oeste do Paraná (UNIOESTE), Toledo, PR - Brasil, e-mail: horacio4@ hotmail.com

\section{Resumo}

Nosso objetivo é, por meio de algumas observações de Wittgenstein sobre crença religiosa, salientar a ética como "sistema de referências". Deste modo, a ética se subtrai de qualquer interpretação de caráter absoluto. Pensar a religião como "sistema de referências" nos permitirá entender o comportamento prático como algo regrado, mas não no modo da prescrição universal. Assim, a ética e a religião terão um papel fundamental no nosso comportamento prático cotidiano, no sentido de alimentar a certeza de nossos juízos práticos. Não obstante isso, Wittgenstein parece enfatizar que, junto com as doutrinas éticas e religiosas que aprendemos ao aprender uma linguagem, deve haver um espaço para a autonomia, entendida como luta ou revolta diante das doutrinas tradicionais.

Palavras-chave: Ludwig Wittgenstein. Ética e Linguagem. 


\section{Abstract}

Our objective is, through some observations of Wittgenstein about religious faith, to point out the ethics as "system of references". This way, the ethics is subtracted of any interpretation of absolute character. To think the religion as system of references will allow to understand the practical behavior as something ruled, but not in the way of the universal prescription. Like this, the ethics and the religion will have a fundamental paper in our daily practical behavior, in the sense of feeding the certainty of ours practical judgements. In spite of that, Wittgenstein seems to emphasize that, with the ethical and religious doctrines that we learned when we learned a language, it should have a space for the autonomy, understood as fight or strong disagree in front of the traditional doctrines.

Keywords: Ludwig Wittgenstein. Ethics and language.

\section{ABREVIAÇÕES}

CV - Cultura e valor

DC - Da certeza

IF - Investigações filosóficas

MP - Movimientos del pensar

NB - Notebooks 1914-1916

TLP - Tractatus lógico-philosophicus

Z - Zettel

A solução do problema que você vê na vida é viver de tal maneira que desapareça o problemático. Dizer que a vida é problemática significa que a tua vida não se ajusta à forma da vida (Form des Lebens). Em consequiência, você deve mudar sua vida e, se ajusta-se à forma, desaparece o problemático. Mas, acaso não sentimos que quem não vê ali um problema está cego frente a algo importante? Não gostaria, acaso, dizer que esse tal vive - precisamente cego, como uma toupeira e que se pudesse ver, veria o problema? Ou não devo dizer que quem vive corretamente não experimenta o problema 
como tristeza, quer dizer, como algo problemático, senão, como uma alegria; ou melhor, como um ligeiro éter em volta a sua vida e não como um entorno duvidoso.

Ludwig Wittgenstein (CV, 1937)

Influência direta da leitura de The varieties of religious experience, de William James, Wittgenstein sempre reconheceu o papel de suma importância que a religião tem na vida do homem, na formação da sua subjetividade. Esta importância, porém, não é tanto psicológica - como no caso do pensador americano -, quanto ética. Se a sensação de admiração ante a existência do mundo - por exemplo - pode ser explicada psicologicamente, é algo que não parece preocupar realmente a Wittgenstein e sim como respondermos a ela. Responder de um modo religioso parece uma das possibilidades válidas para ele, embora duvide que esse tipo de atitude possa ser aplicado a si próprio. Wittgenstein compartilhava com James a ideia de que a religião devia ser de certo modo antropocêntrica, o que significa em verdade que devia ajudar à obtenção de uma vida melhor nesta terra. É importante notar, porém, o que Cyril Barrett destaca na sua Ética y creencia religiosa en Wittgenstein e que compartilhamos: Wittgenstein se encontraria atravessado pela ambiguidade de que entender os preceitos divinos em termos humanos seria em certo sentido um empobrecimento do religioso; porém, se tais preceitos não são entendidos em termos humanos, como o faremos? (BARRETT, 1994, p. 291).

Existe um perigo claro no fato de tornar humana, "demasiadamente humana", a religião: o caso daqueles que apenas podem aceitar os eventos que a Bíblia narra a partir de uma confirmação histórica. Wittgenstein é taxativo sobre isso e afirma em Lições e conversações sobre estética, psicologia e crença religiosa que: "O cristianismo não tem base histórica no sentido de que a crença ordinária em fatos históricos possa servir-lhe de fundamento." (WITTGENSTEIN, 1992, p. 134). A crença religiosa não se baseia em razões como podem basear-se outro tipo de crenças ordinárias. O fato de não ter razões é o seu fundamento e a autenticidade de uma crença - no "Juízo Final" por exemplo - será demonstrada pelo modo em que ela regula o agir de uma pessoa. Não é necessária a acumulação de fatos históricos, ou de provas científicas para alcançar a fé, quem a alcança deste modo pode perdê-la por uma prova contrária, a controvertida idade do Santo Sudário, por exemplo. O critério 
para identificar se uma pessoa possui determinada crença religiosa apenas pode ser a posteriori: o modo em que ela vive. Uma vez mencionado isso, dizemos que para Wittgenstein o ético e o religioso são atitudes ou modos de vincular-se com o que está além da razão. Ao contrário do que possa parecer, esta não é uma observação metafísica senão gramatical: com aquilo que está "além", refere-se Wittgenstein ao momento em que esgotados os fundamentos chegou à rocha dura onde a pá se entorta (IF, 1999, p. 217). As explicações são desnecessárias, ao sumo um requisito arquitetônico, e resta simplesmente nosso modo de agir.

A conexão ético-religiosa que queremos enfatizar não significa a inserção da esfera religiosa no campo prático - por uma influência da interpretação religiosa do destino do homem que faça recomendável que as ações deste, ações morais, sejam dirigidas pelo dogma religioso - senão, pelo contrário, que o agir humano é o que dará sentido a algumas doutrinas religiosas. A obscuridade intrínseca a algumas destas doutrinas apenas pode ser esclarecida pelo modo em que os crentes as vivem.

Acreditamos que se a religião era vista como um choque de vontades (a vontade alheia ou Deus e a minha própria vontade) (NB, 1969, p. 8/7/16), posso estabelecer uma relação - marcada pelo silêncio, é claro com essa vontade, se entro em concordância com o mundo, ou posso discordar e cair na infelicidade. Esta relação com o divino é claramente ética e o ético tem a ver com a dignidade do homem, ${ }^{1}$ o qual põe na tela de julgamento uma visão de submissão do criador na direção da sua criatura. Isso precisa ser esclarecido: é a partir da sua relação com o religioso que poderemos entender - ao menos geneticamente - o que propomos aqui como ética no sentido de "sistema de referências". Se os pontos de contato entre religião e ética foram sempre tão fortes em Wittgenstein, mais que lamentarmos pela escassez de comentários sobre a ética, devemos ver até onde os comentários - mais numerosos - sobre a religião e a fé podem nos servir.

Uma anotação que Wittgenstein faz em 1947 ilustra um pouco mais esta relação entre o comportamento ético e a teoria religiosa: "Pareceme que uma fé religiosa poderia ser algo assim como o apaixonado decidirse por um sistema de referências (Bezugssystem). Como se além de ser fé, fosse uma forma de vida ou uma forma de julgar a vida [...]" (CV, 2000a, p. 1947). Outro momento no qual fala de "sistema de referências"

1 Dignidade no sentido kantiano de quem se dá a si mesmo, pelo menos por meio da dúvida ou revolta contra a linguagem, os critérios da ação prática. 
(Bezugssystem) é nas Investigações filosóficas onde, imaginando a situação na qual um explorador chega a um país desconhecido com uma língua completamente estranha à sua, interpreta tal língua utilizando o modo de agir humano comum (die gemeinsame menschliche Handlungsweise) como sistema de referência (IF, 1999, p. 206).

Poderíamos dizer que quando a vida "fala uma linguagem estranha", quando não se ajusta à "forma de vida" (lembrar fragmento na epígrafe) torna-se problemática para nós. A religião é entendida como um meio que nos ajuda a movimentar-nos através desse problema: consolando, animando e recriminando-nos pelas nossas ações ou omissões. Os momentos que a religião outorga podem ser agradáveis (sensação de estar protegido ou salvo graças ao poder divino) ou desagradáveis (sentir-se culpado por não cumprir com o que Deus "espera" de nós). Curiosamente, ou não tanto, Wittgenstein (1995) fala dessas duas sensações quando dá a sua Conferência sobre a ética no seu retorno à Cambridge em 1929. ${ }^{2}$

E este é o misticismo de Wittgenstein: um recurso real - no qual real significa não metodológico, muito menos, retórico - pelo qual as perguntas e as questões que o homem pode se fazer ficam restritas. ${ }^{3} \mathrm{~A}$ palavra Deus nas anotações de Wittgenstein não significa tanto um criador responsável de suas criaturas, quanto a denominação de uma "região" onde as perguntas - e sobretudo a pergunta sobre a finalidade da vida são impossíveis. Deus é, portanto, mais um limite antropológico (diz mais a respeito da natureza do homem) que um agente suprassensível.

2 A Conferência sobre a ética se erige sobre a divisão da obra wittgensteiniana entre uma primeira e uma segunda filosofia. Esta afirmação não se fundamenta apenas no fato cronologicamente claro - de ser o seu primeiro texto a partir do seu retorno à Cambridge. Também o faz no fato de manter junto com a distinção tractariana do dizer e mostrar e a consequente impossibilidade de expressar enunciados éticos, a utilização-metodológica - de uma diversidade de exemplos para chegar não à essência do conceito, mas ao que estes exemplos têm em comum. Acreditamos que aí reside um ponto importante de inflexão do pensamento wittgensteiniano em relação ao mundo dos valores: na época do Tractatus, o objetivo de seu autor era o de "subtrair" o absoluto (ético, religioso, estético) das mãos dos filósofos, e era isto no que consistia o seu "tão célebre" ataque à metafísica. Na Conferência sobre a ética parece se preocupar não apenas desta tarefa senão também - de uma forma positiva - por entender que estas proposições ou discursos formam parte da vida em sociedade.

3 “No Tractatus, o inefável não é um recurso tardio, post factum. Tampouco Deus, o Altíssimo, um complemento irrelevante ou gratuito, como se fora uma herança filosófica mal digerida ou aquele preço elevado que, tendo-a superado, ainda deveríamos pagar à metafísica [...]" (SALLES, 2006, p. 105). 
Se o segundo Wittgenstein não recomenda o silêncio sobre alguns assuntos é porque prefere demonstrar o vazio sobre o qual giram certas perguntas - e suas respostas -, sua falta de "solo", o "torrão natal", de Heimat (IF, 1999, p. 116). Na antropologia do Tractatus destacava-se um sujeito metafísico do qual não se podia falar, embora fazia o seu mundo, e desde que era um sujeito solipsista, o mundo. O assim chamado "segundo" Wittgenstein desiste do "aparelho" de subjetividade schopenhaueriana, porém não da "sem-razão" que o dirige. Entretanto, a preferência de Wittgenstein pela frase de Goethe: "Im Anfang war die Tat" (DC, 2000b, p. 402) coloca a não-racionalidade na base e origem do mundo segundo o autor das Investigações, o mundo dos jogos de linguagem. Este mundo já não vem de um esquema lógico a priori, mas de um movimento, de uma ação, e isto é o que caracterizará o pensamento maduro do filósofo vienense: a inserção do prático, dos usos e dos costumes na relação com o mundo. Se a certeza infundada está na base de nossos jogos de linguagem já não é preciso um sujeito transcendental que possa intuir os limites do mundo, já que estes serão imanentes ao agir do sujeito desses jogos de linguagem.

O ético e o religioso parecem se aproximar até a quase completa identificação na obra de juventude, assimilar-se aos fatos do mundo que eram a vida, era assimilar-se a Deus. A pergunta pelo sentido da vida era uma dolorosa questão a resolver pelo esquecimento de tal pergunta, pelo silêncio. Um Wittgenstein mais maduro parece reclamar do religioso uma maior autonomia para o homem, uma autonomia sem imperativos.

O exemplo mais claro disto é o rechaço à doutrina da predestinação, segundo a qual algumas almas vão para o céu e outras não, conforme a vontade do criador. Algumas almas que recebiam a graça de Deus eram premiadas e as que não recebiam tal graça eram punidas. Wittgenstein diz a este respeito:

Suponhamos que se tenha ensinado a alguém: há um ser que se você faz "isto ou aquilo", ou se você vive "assim ou assado" te levará a um lugar de tormentos eternos depois da tua morte; a maioria das pessoas terminam neste lugar, uns poucos vão a um lugar de felicidade eterna. Esse ser tem selecionado de antemão os que têm que ir ao lugar bom e, colocado que, apenas as pessoas que têm levado um certo tipo de vida vão ao lugar de tormentos; também tem arranjado de antemão que os outros vivam assim. Qual seria o efeito dessa doutrina? Bem, não menciona o castigo, senão uma espécie de necessidade natural. E se você apresenta as coisas desse modo a alguém, este só poderia reagir com desespero ou incredulidade ante essa doutrina (CV, 2000b, p. 1949). 
Esse sistema de prêmios e castigos das ações morais foi explicitamente rechaçado no Tractatus (TLP, 1994, p. 6.422), embora ele falasse que se houvesse algum prêmio ou castigo no agir prático este deveria ser intrínseco a tal agir, uma espécie de sensação agradável para uma boa ação ou desagradável no caso contrário. Wittgenstein tenta, na época do Tractatus, substituir o "bem" e o "mal" pela felicidade ou a infelicidade do agente (TLP, 1994, p. 6.422).

Neste caso, a anotação parece reclamar que não se pode fazer nada com um tipo tal de doutrina. Se dissemos que a religião é um sistema de referências, o é porque em determinadas circunstâncias pode nos ajudar numa decisão, num problema prático.

Quando se fala do caráter prático da segunda filosofia wittgensteiniana é porque encontramos nela seguimento de regras, conhecimento e uso de técnicas, contextos nos quais e a partir dos quais se praticam diferentes jogos de linguagem: se fazem perguntas, se responde, se nega, se brinca, se tomam decisões. Quando se afirma que seguimos uma regra cegamente e se aponta ao modo comum e geral do agir humano, não está se realizando uma nova fundação - neste caso behaviourista significando que em lugar da razão devemos colocar o instintivo, biológico ou simplesmente animal na essência do que fazemos. Em todo caso, está combatendo-se a imagem comum da palavra regra, qual é a de uma prescrição que seguimos racionalmente, conscientemente. Se bem que, é claro que existem regras explícitas as quais adotamos em algum momento de nosso agir; o que Wittgenstein está apontando são as regras implícitas em nosso ser em sociedade, as técnicas que usamos cotidianamente.

A doutrina da predestinação - tal qual a entende o filósofo vienense - ataca pela base a ideia de um sujeito que age no tecido de relações humanas com independência de entidades transcendentes. A ideia de um sujeito determinado essencialmente, a priori, no seu agir, a ideia de uma necessidade nos atos parece produzir um forte rechaço em Wittgenstein:

Uma lei moral natural não me interessa; ou não mais que qualquer outra lei natural e não mais que aquela pela qual uma pessoa transgride a lei moral. Se a lei moral é natural eu me sinto inclinado a defender o transgressor (MP, 2000c, 22/01/31).

Acreditamos que Wittgenstein é partidário de uma "contingência regrada". Haveria uma total ausência de "telos" nos atos de um homem e de uma sociedade: tudo poderia ser de outra maneira, já que o seguimento de 
uma regra não torna necessário um acontecimento, senão possível. O caráter cultural das regras, a sua formação a partir de "formas de vida" destaca o seu aspecto convencional, nenhuma regra é necessária em sentido absoluto: dada outra cultura seriam outras as regras, os acontecimentos e a nossa imagem deles. De qualquer maneira, o que Wittgenstein parece combater é novamente a ideia de que nossos atos vão receber um julgamento divino, um julgamento heterônomo. A realização de um ato segundo as suas consequências éticas, um prêmio ou um castigo, a transformação do religioso numa ética prescritiva é o que condena o filósofo:

Como julgue Deus a um homem é algo que nem podemos imaginar. Se realmente toma em conta a força da tentação e a fragilidade da natureza, a quem pode condenar? De outro modo, o resultante dessas duas forças é simplesmente o fim ao que o homem estava predestinado. Nesse caso foi criado de maneira tal que a inter-relação de forças o faria vencer ou sucumbir. E essa não é em absoluto uma idéia religiosa, senão algo mais parecido a uma hipótese científica. Assim, se queres permanecer dentro da esfera religiosa tens que lutar (CV, 2000a, p. 1950).

Wittgenstein quer subtrair o elemento religioso tanto do ataque racionalista, do ataque argumentativo que acaba (des)qualificando-o de irracional, ${ }^{4}$ quanto da tentativa de justificar racionalmente tal elemento. $\mathrm{O}$ que significaria lutar nestas circunstâncias? Wittgenstein assinala em outro lugar que há diversos graus de fé, e que no grau em que ele estava não precisava da doutrina da predestinação.

A religião cristã é apenas para o homem que precisa uma ajuda infinita, somente, ou seja, para o homem que experimenta tormentos infinitos. [...] A fé cristã - tal e como a concebo - é o refúgio do homem em seu último tormento (CV, 2000a, p. 1946).

Um homem em circunstâncias normais deveria poder saber escolher o que aceita e o que não, do credo cristão. Ora, numa situação de extrema dor ou numa decisão extrema talvez pensar que o seu destino estava marcado, resulte um alívio para ele. Nessa situação já não há luta, o homem se entrega à fatalidade do momento; Wittgenstein reivindicava para si mesmo

4 Wittgenstein sempre fala da religião como "não-racional", já que o termo "irracional" tem algo de pejorativo (WITTGENSTEIN, 1992, p. 134). 
a oportunidade de escolher (segundo o seu grau de fé) o que aceitava e o que não, do seu credo. Lutar dentro da esfera do religioso significaria, então, não aceitar sem mais qualquer doutrina ou forma de devoção. Lutar é conquistar essa convicção que não pode nunca ser objetiva.

A doutrina da predestinação - porém - não afirma que o homem esteja predeterminado no seu agir. A liberdade de escolha é o que marca essencialmente a criatura enquanto tal. E ainda seja que estivesse predestinada ao mal, ela não o saberia mais que enfrentando a tentação, portanto, o dito confronto deve ser realizado de todos os modos. ${ }^{5}$ Talvez seja a ideia de "Juízo Final" a que mais irrite a Wittgenstein. ${ }^{6}$ Para ele, talvez Deus não estivesse morto, mas sim aposentado da sua potestade. Se os valores estão inevitavelmente fora do mundo (TLP, 1994, p. 641) ou caem no campo do que pode ser acreditado, mas não conhecido ou sabido (DC, 2000b, p. 111), a imagem de um Deus Padre, condenando ou premiando os atos humanos, não traz esses valores ao mundo senão sob a forma do "dever". Tal ideia influiria negativamente sobre o poder de decisão humana, que é o que Wittgenstein parece defender como marca de individualidade. Isso aparece maravilhosamente resumido na sua frase: "Não posso ajoelhar-me para rezar, meus joelhos estão rígidos - por assim dizer - temo a dissolução, (a minha dissolução) se o faço" (CV, 2000a, p. 1946) Também numa anotação anterior dirá algo similar: "Se ajoelhar significa ser um escravo (Em isto poderia consistir a religião.)" (MP, 03/03/37).

Ao jovem Wittgenstein, a falta de valores - sua inexpressabilidade - leva-o a procurar uma total assimilação aos fatos do mundo, uma apatia que o liberasse da decepção e do sofrimento. O sujeito metafísico do Tractatus, sujeito portador da ética e solipsista, torna-se um ponto sem extensão. Se levarmos esta figura ao extremo, o sujeito ético do Tractatus é sujeito em dissolução: sua única função é apreender e se identificar com os limites do mundo, a consecução do silêncio. Já para o Wittgenstein das Investigações, essa mesma inexpressabilidade torna impossível qualquer teoria ética única. Essa impossibilidade não gera apatia senão que libera a seu arbítrio a decisão do protagonista de um determinado

Tentamos abordar a relação problemática entre livre-arbítrio, graça e predestinação em nosso artigo "Livre arbítrio e vontade na obra O livre-arbítrio de Santo Agostinho "Horacio Luján Martínez, Revista Varia Scientia, agosto 2002 (p. 59-66).

6 'Preferiria escutar: 'Se não fazes isso desaproveitarás a vida', que: 'Se não fazes isso serás castigado'. O primeiro significa propriamente: Se não fazes isso tua vida é mera aparência, não tem verdade e profundidade" (MP, 2000c, 18/02/37). 
problema. Isto não seria "decisionismo" no sentido em que a autoridade de uma primeira pessoa, um sujeito forte, legitima-se a decisão ética tomada numa circunstância dada. A necessidade da decisão surge a partir da total falta de critérios absolutos para determinar o que está bem e o que está mal.

$\mathrm{Na}$ continuação ilustraremos melhor isso, já que falamos até agora de decisões no que concerne à crença religiosa, mas não demonstramos se acontece o mesmo no campo estritamente ético.

No artigo "La concepción wittgensteiniana de la ética", de Rush Rhees, ele transcreve conversas mantidas com Wittgenstein ${ }^{7}$. Nessa ocasião, Wittgenstein considera três exemplos: o assassinato de Julio César em mãos de Bruto (era algo nobre como queria Plutarco ou uma má ação como afirmou Dante?); a questão de se um homem tem direito a se deixar matar pela verdade e o terceiro exemplo é o dilema que enfrenta um homem que deve decidir entre deixar a sua esposa ou abandonar sua pesquisa sobre o câncer. Os dois primeiros não são sequer problemas éticos para Wittgenstein, e não o são porque não podemos saber o que passa pela cabeça dos agentes de tal ação nesse momento. Isto não quer dizer que Wittgenstein reivindica o conteúdo psicológico como critério legitimador de uma ação moral. O que põe em evidência é o que acabamos de mencionar como "a total falta de critérios absolutos para a escolha ética": é o sujeito quem tem que escolher num determinado momento. A respeito do terceiro exemplo, segundo uma ética cristã, a solução está perfeitamente clara: deve continuar com a sua mulher aconteça o que aconteça. Então alguém poderia perguntar se o tratamento dado pela ética cristã é o certo ou não. Talvez uma ética de inspiração nietzschiana desse uma resposta absolutamente contrária à cristã, a ideia que aparece num primeiro momento é que se deveria poder decidir qual das duas éticas é a mais correta, ao que Wittgenstein responde:

Mas não sabemos como seria tal decisão, como se determinaria, que classe de critérios usar-se-ia, e assim sucessivamente. É comparável a afirmar que deve de ser possível decidir qual é o mais correto entre dois modelos de precisão. Nem sequer sabemos o que pretende quem formulou tal pergunta (WITTGENSTEIN, 1990, p. 59).

Retomou esta questão da "ética correta" mais tarde. O fez numa ocasião (1945) quando estava discutindo as relações entre ética, psicologia e sociologia.

Publicadas na Conferência sobre a ética na versão em espanhol (WITTGENSTEIN, 1990). 
As pessoas tiveram a noção de uma teoria ética, a idéia de encontrar a verdadeira natureza da bondade ou do dever. Platão quis fazer isto dirigir a pesquisa em direção à busca da verdadeira natureza da bondade - para conseguir objetividade e evitar relatividade. Pensou que a relatividade devia evitar-se de qualquer forma, devido a que destruiria o imperativo em moralidade (WITTGENSTEIN, 1990, p. 59).

Wittgenstein está assinalando que se afirmamos que a ética cristã é a correta, na realidade estamos fazendo um juízo de valor, adotamos essa ética como correta. Não é o mesmo que afirmar que entre várias teorias físicas uma é a mais correta, já que os modos de contrastá-las são diferentes.

O que Wittgenstein parece nos dizer é que qualquer ação ética premeditada que realizemos será simplesmente o fruto da escolha entre éticas possíveis. Porém, esta escolha não está orientada por um "bem absoluto". Como é esclarecido na Conferência sobre a ética, se existisse um estado de coisas descritíveis como um bem absoluto, este não poderia deixar de ser procurado, nos sentiríamos em falta se não o fizéssemos. Mas não existe nenhum estado de coisas com tal poder restritivo.

Esta carência de tal referente metafísico pode - segundo alguns - nos deixar às portas do niilismo. Como manter uma escolha sem transcendência e a sua vez conviver com as escolhas dos outros? A falta de um valor absoluto - monolítico - faz pensar a muitos na absoluta falta de valores. A posição relativista ou situacionista de Wittgenstein pareceria nos abandonar aos braços de um paradoxo, o qual seria o de precisar uma educação ética para depois nos comportar segundo nossa eleição.

Uma questão importante, que pode arrastar-se numa primeira aproximação ao paradoxo, é a caracterização da moral como algo que deve ser seguido incondicionalmente. Quando percebemos que isto é impossível, é provável cair no ceticismo ou niilismo individualista: dada a impossibilidade do seguimento absoluto das regras de qualquer doutrina ética, tal doutrina é impossível, portanto entrego-me à defesa dos próprios interesses (uma espécie de egoísmo pré-contratualista como essência do homem). É interessante ver como a projeção de eventos futuros realizada quando se fala de relativismo moral é sempre apocalíptica. ${ }^{8}$

Assim afirma Robert L. Arrington no seu artigo "A defense of ethical relativism": "As objeções ao relativismo são, na maioria das vezes, basicamente predições sobre o que aconteceria se o relativismo fosse aceito." (ARRINGTON, 1983, p. 236). 
Mas Wittgenstein sugere um exercício de ponderação quando diz que a doutrina da predestinação não é um ensinamento ético, é mais como um mistério incompreensível que deve ser dado a conhecer depois de uma educação ética $(\mathrm{CV}, 2000 \mathrm{a})$. A doutrina da predestinação com o respectivo "Juízo Final" que a consagra, nos determina a certo tipo de comportamento em função do medo à reprovação divina. Se o cristianismo afirma que fomos feitos a imagem e semelhança de Deus, o conteúdo da nossa vida deve ser medido segundo um molde divino, isso nos condena à santidade, à hipocrisia ou ao cinismo. Por isso, Wittgenstein considerava - na sua interpretação - que o cristianismo só podia ser adotado em situações extremas, dor extrema ou um enorme desespero.

O que a "decisão", que salientamos como opção, erige não é a firmeza ou autenticidade da primeira pessoa, senão a falta de critérios para distinguir qual ética é a correta.

Mas, será que Wittgenstein compartilhava a afirmação de Nietzsche, de que não há fenômenos morais, mas a interpretação moral dos fenômenos?? Acreditamos que não, os fenômenos morais existem os exemplos citados anteriormente o demonstram -, o que não haveria é uma resposta moral a esses fenômenos, quer dizer, uma única resposta: uma doutrina que resolva claramente tais problemas. Há problemas morais, embora não uma moral. O moral e o religioso partilham a mesma falta de critérios para determinar a sua "eficiência", a consecução de um efeito por meio do seguimento de uma norma ou crença.

Wittgenstein, porém, rechaça a teorização da moral, já que a considera impossível: sua evidente falta de critérios para determinar o "bem" e o "mal" não é uma carência a ser solucionada posteriormente - por uma esperada evolução do espírito humano - senão que constitui o ser mesmo da ética. O ético e o religioso apenas podem ser "sistemas de referências" (Bezugssystemen) e não um conjunto de prescrições a serem obedecidas. O paradoxo já citado, de precisar de uma doutrina moral para determinar não segui-la, se dissolve com a distinção feita na Conferência sobre a ética entre juízo de valor relativo e juízo de valor absoluto. Enquanto posso jogar mal ao tênis e não querer jogar melhor - ao que meu companheiro de jogo não teria nada que reprovar -, não posso me comportar de uma forma escandalosamente corrupta sem ser admoestado, sem que alguém reclame que deveria querer me comportar de outro modo. Ou seja, não existe para

9 Ver O ocaso dos idolos, tópico “Os 'melhoradores' da Humanidade” parágrafo 1. 
Wittgenstein um bem absoluto com poder coercitivo, isto é, que uma vez conhecido não possa deixar de ser realizado. $\mathrm{O}$ "segundo" Wittgenstein pareceria se aproximar a um relativismo ético, sem que por isso se vincule estritamente com essa corrente. O que tal relativismo significaria é que não existe uma moral, senão que a moral é mais um "jogo de linguagem", um "sistema de referências" com o qual agimos, falamos, acusamos ou admiramos os atos próprios e alheios. ${ }^{10}$ Como todo jogo que não seja espetáculo envolve somente seus participantes. Para dar maior precisão a esta afirmação, nos apoiamos no artigo de Darlei Dall'Agnol "Jogos morais de linguagem". Neste texto, Dall'Agnol salienta como todo jogo moral de linguagem possui seus próprios padrões de correção e objetividade. Nem todo jogo moral de linguagem precisa ter caráter prescritivo universal (DALL'AGNOL, 2006, p. 68). ${ }^{11}$

Para Wittgenstein, não haveria nenhuma necessidade ou mérito em universalizar um conceito ético, tal conceito só pode nascer a posteriori (a partir de "formas de vida") e, portanto, já é universal (ou melhor, já é "regional", não pertence à humanidade senão a um grupo determinado). Desse modo, embora seja uma questão que não poderemos aprofundar aqui, não vemos porque quereríamos nem como poderíamos implementar uma ética universal. Se todos tivéssemos quisto ou ambicionado o mesmo, essa ética já teria sido alcançada - apesar de qualquer suposta divisão da natureza humana - e não haveria conflitos morais. O caráter incompleto de qualquer ética - o ser discutível, o ser relativo, o não resolver um conflito de um modo absoluto - é o seu centro mesmo. O ser ético não consiste em fazer "o bom" senão em assumir a própria decisão num juízo de valor, enfrentar o conflito como o núcleo mesmo da vida. Por isso, no campo da ética wittgensteinianamente entendida, devemos distinguir o ato de seguir uma regra segundo o sistema de referência cristão ou nietzschiano, p.e., e a decisão individual. Num conflito ético não sigo a regra cegamente, mas realizo uma

\footnotetext{
10 Assim opina também Cyril Barrett: "Wittgenstein defendeu uma forma moderada e razoável de relativismo ético: a saber, que quando existem conflitos morais não há nenhum critério ou princípio superior, prevalente e absoluto, nesse sentido, que decida, de uma vez por todas, entre as concepções enfrentadas." (BARRETT, 1994, p. 305). Podemos acrescentar que este relativismo "moderado e razoável" que Barrett outorga a Wittgenstein não é mais do que a constatação da diversidade de opiniões no campo do pensamento prático.

11 Dall'Agnol (2006) parece enfatizar o caráter externalista dos jogos morais de linguagem, posição que compartilhamos, embora nosso texto focalize o caráter individual (que não significa interno) da decisão.
} 
ponderação tendo a cultura a que pertenço como pano de fundo. Uma cultura - entendida como o conjunto orgânico das "formas de vida" - dá as premissas (algumas delas tradicionais, por que não?) que os indivíduos podem seguir. A responsabilidade da escolha ética une minha autonomia ${ }^{12}$ com o pertencer a uma cultura determinada. Tal responsabilidade é parte da cultura e não é necessária de um modo heterônomo, quer dizer, dissolvemos o paradoxo antes apresentado, afirmando que não é que precisamos duma educação ética tradicional (com os seus deveres, proibições e culpas concomitantes) para extrair dela o sentido de responsabilidade antes de alterá-la. O fato é que temos educações éticas tradicionais - acreditamos que ninguém viveria com uma escala de valores lida no jornal do último domingo - e, portanto, mexemos, criamos com ela: "Quero dizer: uma educação absolutamente diferente à nossa também poderia ser o fundamento de conceitos completamente diferentes." (Z, 1985, p. 387). A responsabilidade não é o "dever" encoberto, senão uma regra tácita da nossa cultura e que posso determinar seguir e se dá sob a forma "assumo esta escolha".

A "tradição" dará o material para diferentes decisões em diferentes "jogos de linguagem", um deles, o "jogo de linguagem" da moral. O problema é - uma vez que colocamos a ética como mais um jogo de linguagem - se não terminamos identificando o "bem" e o "mal" com o que está aprovado por uma sociedade determinada. ${ }^{13}$

O que podemos dizer aqui é que Wittgenstein não está sugerindo um tal exercício de "ponderação dissidente" como uma ética a seguir. De fato, as apreciações sobre a ética que realiza na sua maturidade surgem como resposta à pergunta: que ética é correta? - precisamente para rechaçar tal pergunta. A ideia wittgensteiniana foi sempre a de um individualismo ético, que consistiria neste caso em não seguir mecanicamente uma doutrina sem antes passar pela revisão pessoal do tipo: como ela muda a minha vida?

12 Utilizamos conscientemente o termo "autonomia" no sentido kantiano de se dar a própria lei (critério neste caso) moral. Só que esta autonomia dependerá do faktum da linguagem como forma pública e compartilhada de razão.

13 Javier Sádaba, no capítulo "Ética analítica" da Historia de la Ética afirma que o jogo de linguagem ético é o jogo básico, porque é o suposto de toda comunicação. Embora não desenvolva isso, o imaginamos perto da opinião de Hilary Putnam, de que as "formas de vida" e os "jogos de linguagem" precisam de certa empatia e tolerância para funcionarem. Essas características colocariam a ética na base do funcionamento de toda a linguagem (PUTNAM, 1999, p. 73-75). Por enquanto, deixamos essas opiniões como interrogações. (SÁDABA, 2008, p. 172). 
O caráter conflitivo da vida parece o centro inevitável do que o filósofo vienense compreende por ética, embora para tal conflito não existam remédios universais. Como já foi mencionado, não temos aqui solipsismo: a decisão se realiza a partir do pertencer a uma cultura. De qualquer maneira, não existe legitimação do meu agir pela coincidência (universalização) com o que esta cultura erige como valores. Como vimos, no caso da doutrina da predestinação, nada me impede criticar uma teoria e decidir não optar por ela (e nesse caso estaria jogando um outro jogo e com outros participantes, um jogo diferente dos que acreditam e precisam tal teoria como guia).

A título de conclusão, podemos dizer que o "primeiro" Wittgenstein era um subjetivista ético: os fatos adquiriam o seu caráter a partir da nossa visão sobre eles.

Já na obra de maturidade, o filósofo acha que um fato pode ser conflitivo e pode ter uma determinada solução a partir do "sistema de referências" de uma moral, religião ou cultura específicas. Isto nos deixa com a ideia de que Wittgenstein era um relativista. Mas seria isso tão claro assim? Se a linguagem está constituída por práticas cotidianas e estáveis, é difícil determinar se estas práticas formam regras e critérios de matiz realista, relativista ou de alguma instância intermediária.

Para resumir, afirmamos que a vida como problema e tarefa foi sempre o centro do pensamento ético wittgensteiniano. De uma solução por dissolução - marcada por uma busca incondicional da apatia - à convivência com tal problema derivada de um trabalho sobre si mesmo, vemos o percurso da sua consideração prática. "Diga-lhes que tive uma vida maravilhosa!", foram as últimas palavras de Wittgenstein, segundo consta na memória de Norman Malcolm (MALCOLM, 1966, p. 100). Palavras que, mais do que descrever um fato, exibem a conviçção pela qual o filósofo teve que lutar.

\section{REFERÊNCIAS}

ARRINGTON, R. L. A defense of ethical relativism. Metaphilosophy, v. 14, n. 3-4, p. 225-239, 1983.

BARRETT, C. Ética y creencia religiosa en Wittgenstein. Tradução de Humberto Marraud González. Madrid: Alianza, 1994.

Jogos morais de linguagem. In: MORENO, A. R. (Org.) Wittgenstein: ética, estética, epistemologia. Campinas: Ed. da Unicamp, 2006. 
MALCOLN, N. Ludwig Wittgenstein: a memoir (With a Biographical Sketch by George Henrik Von Wright). London: Oxford University Press, 1966.

PUTNAM, H. El Pragmatismo: un debate abierto. Tradução de Roberto Rosaspini Reynolds. Barcelona: Gedisa, 1999.

SÁDABA, J. Ética analítica. In: CAMPS, V. (Ed.). História de la ética. 3: la ética contemporânea. Barcelona: Crítica, 2008.

SALLES, J. C. O retrato do vermelho e outros ensaios. Salvador: Quarteto, 2006.

WITTGENSTEIN, L. Notebooks 1914-1916. Oxford: Blackwell, 1969.

Zettel. Tradução de Octavio Castro e Carlos Ulises Moulines. México: UNAM, 1985.

Conferencia sobre ética: con dos comentários sobre la teoria del valor. Tradução de Fina Birulés. Barcelona: Paidós, 1990.

Lecciones y conversaciones sobre estética, psicologia y creencia religiosa. Tradução de Isidoro Reguera. Barcelona: Paidós, 1992.

Tractatus lógico-philosophicus. Tradução de Luiz Henrique Lopes dos Santos. São Paulo: EDUSP, 1994.

Conferência sobre ética. In: DALL'AGNOL, D. Ética e linguagem: uma introdução ao Tractatus de Wittgenstein. Florianópolis: Ed. da UFSC; São Leopoldo: Ed. da Unisinos, 1995. p. 206-221.

. Investigações filosóficas. Tradução de José Carlos Bruni. São Paulo: Nova Cultural, 1999.

Cultura e valor. Tradução de Jorge Mendes. Lisboa: Edições 70, 2000a.

Da certeza. Tradução de Maria Elisa Costa. Lisboa: Edições 70, 2000b.

Movimientos del pensar. Diarios 1930-1932/1936-1937. Tradução de Isidoro Reguera. Valencia: Pré-textos, 2000c.

Recebido: $15 / 12 / 2008$

Received: $12 / 15 / 2008$

Aprovado: 16/03/2009

Approved: 03/16/2009 